\title{
Post-natal parental care in a Cretaceous diapsid from northeastern China
}

\author{
Junchang Lü* \\ Yoshitsugu Kobayashi \\ D. Charles Deeming
}

Yongqing Liu

\author{
Institute of Geology, Chinese Academy of Geological Sciences, Beijing 100037, China \\ Key Laboratory of Stratigraphy and Paleontology, Ministry of Land and Resources of China, Beijing \\ 100037, China \\ Hokkaido University Museum, Hokkaido University, Sapporo 060-0810, Japan \\ School of Life Sciences, University of Lincoln, Joseph Banks Laboratories, Green Lane, Lincoln, \\ LN6 7DL, United Kingdom \\ Institute of Geology, Chinese Academy of Geological Sciences, Beijing 100037, China \\ Key Laboratory of Stratigraphy and Paleontology, Ministry of Land and Resources of China, Beijing \\ 100037, China
}

group of specialized aquatic and semi-aquatic diapsid reptiles which ranged from Late Triassic to Middle Miocene, and they have been found in North America, East Asia, and Europe (Gao, 2007). Since the first discovery of monjurosuchid Monjurosuchus splendens (Endo, 1940), more and more monjurosuchids have been found and they are widely distributed in the Early Cretaceous Yixian and Jiufotang formations of the Jehol Biota in western Liaoning (Zhang and Gao, 2014). The skeletons are of an apparent adult Philydrosaurus, together with six young individuals of the same species. We interpret this as the first evidence of post-natal parental care in a basal diapsid.

\section{MATERIALS AND METHODS}

\subsection{Preservation of the Specimens (JPM-10-088)}

The specimens (JPM-10-088; Fig. 1) were donated to the Jinzhou Paleontological Museum (JPM) in Jinzhou City of Liaoning Province four years ago by a local farmer, who is not willing to reveal his identity. Preparation was carried out by Y.-Q. Zhang at the Institute of Geology, Chinese Academy of Geological Sciences, Beijing, under the supervision of J. L. Photo documentation of this process by J.L., in particular of early stages of preparation (Fig. 2) at which point, many skeletons were still almost completely enclosed by rock (Figs. 2a and c), and demonstrates that JPM-10-088 is genuine and not a composite.

\subsection{Estimation of the Body Volumes of the Adult and Young Individuals}

We envisage the body concavity as a cylinder, thus according to the formula: Volume $=$ base area $\times$ height, we can estimate the minimum volume of the adult body cavity and of the juveniles' bodies in total. The circumference (c) of the base area is composed of both rib length plus gastral rib length

*Corresponding author: lujc2008@126.com 
Junchang Lü, Yoshitsugu Kobayashi, D. Charles Deeming, and Yongqing Liu
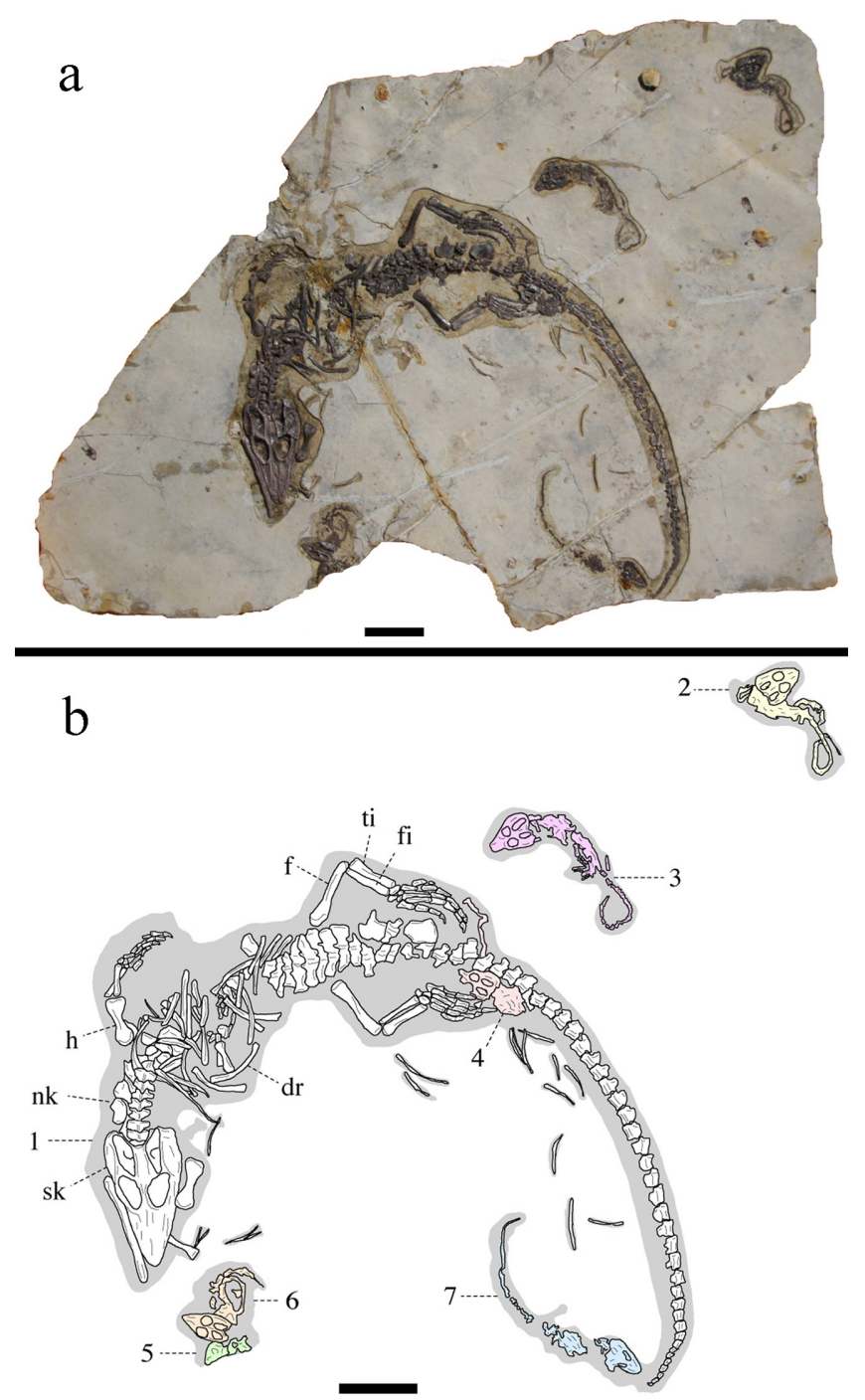

Fig. 1. Photograph (a) and line drawings (b) of Philydrosaurus (JPM-10-088). 1: adult; 2-7: juveniles (see text for diagnosis). Abbreviations: $\mathrm{dr}$ - dorsal rib; $\mathrm{f}-$ femur; fi - fibula; $\mathrm{h}$ - humerus; nk - neck; sk - skull; ti - tibia. Grey areas were exposed during its preparation, demonstrating that all skeletons are from a single horizon. Scale bar $=5 \mathrm{~cm}$.

+ vertebral width, thus the radius (r) of the base area is: $r$ $=\mathrm{c} / 2 \pi$. The length of the vertebral column is used as the height of the cylinder (E). In juvenile animals the dorsal ribs are not fully ossified and so the half skull width is used
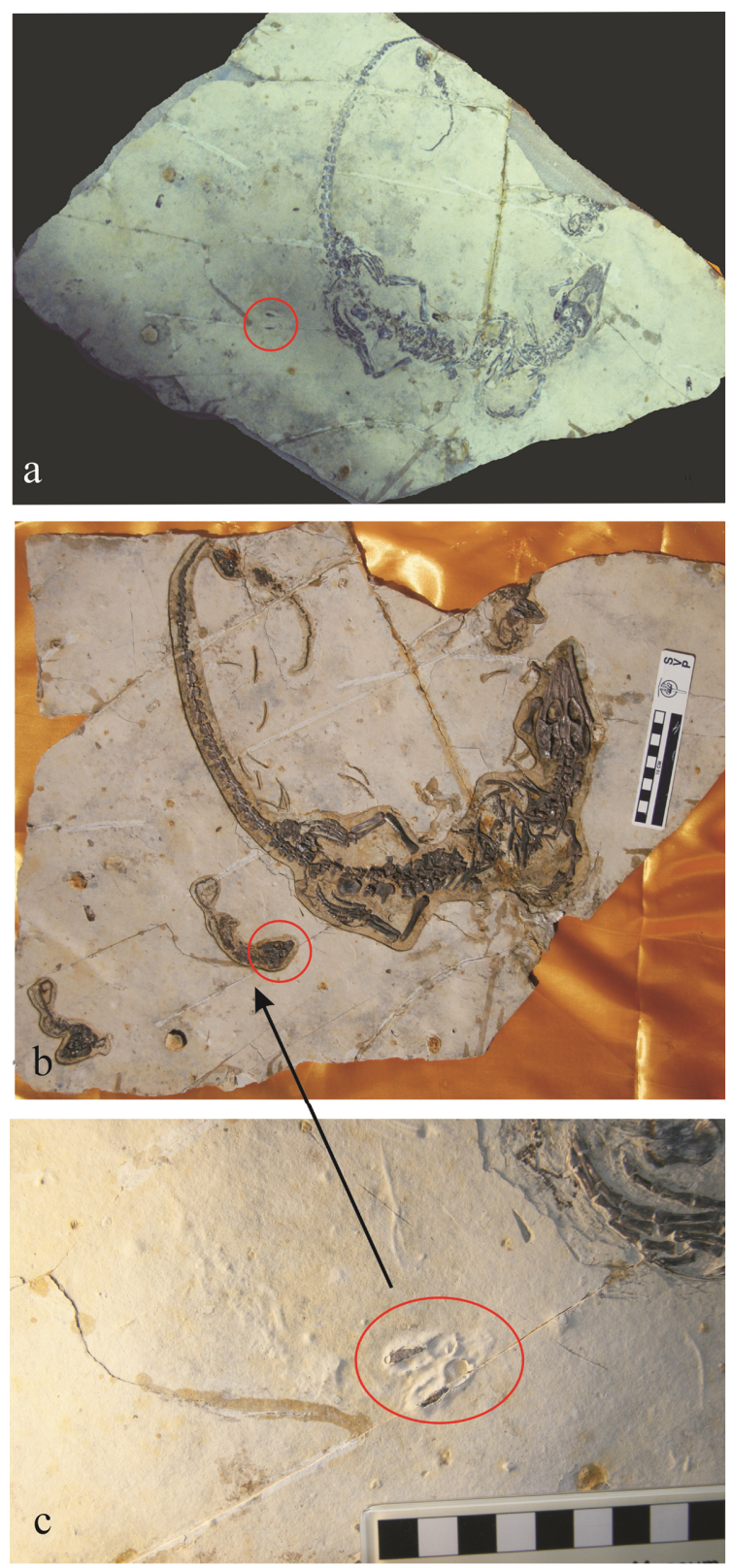

Fig. 2. Specimen (JPM-10-088) before preparation (a and c) and after preparation (b). Red circle points to the skull before preparation and after preparation.

as the radius of the base area. The base area is calculated: (D): $\mathrm{D}=\pi \mathrm{r}^{2}$. The length of the cylinder is supposed to be

Table 1. Estimation of volumes of the adult and young individuals

\begin{tabular}{|c|c|c|c|c|c|}
\hline & RL & GRLVW & $\mathrm{BC}$ & LDVC & REBV \\
\hline Adult & $4 \mathrm{~cm}$ & $3.1 \mathrm{~cm}$ & $14.2 \mathrm{~cm}$ & $10 \mathrm{~cm}$ & $160.5 \mathrm{~cm}^{3}$ \\
\hline & \multicolumn{2}{|c|}{ Average half skull width (HSW) } & Base area $\left(\pi \mathrm{HSW}^{2}\right)$ & & \\
\hline Young & \multicolumn{2}{|c|}{0.993} & $3.097 \mathrm{~cm}^{2}$ & $10 \mathrm{~cm}$ & $30.7 \mathrm{~cm}^{3}$ \\
\hline Six young individuals & - & - & - & - & $185.8 \mathrm{~cm}^{3}$ \\
\hline
\end{tabular}

RL, rib length; GRLVW, gastral rib length plus vertebra width; $B C$, body circumference $((\mathrm{RL}+\mathrm{GRLVW}) \times 2)$; LDVC: length of the dorsal vertebral column; REBV, rough estimate of body volume $\left(\mathrm{BC}^{2} \times \mathrm{LDVC} / 4 \pi\right)$. 
the length of the vertebral column of the adult.

Hence the volume of the adult body concavity is estimated to be $160.5 \mathrm{~cm}^{3}$, whilst the combined minimal volumes of the six young individuals are $185.8 \mathrm{~cm}^{3}$ (Table 1). That the volume of small individuals is greater than the body cavity of the adult without taking into account either the volume occupied by the viscera of the adult, or the limbs and tails of the offspring, strongly suggests that the six young individuals were not neonates.

\section{DESCRIPTION}

The largest specimen is presumed to be an adult and the parent of the six smaller individuals, which we consider as juveniles. Hence we consider this is a family group. The adult skull length (Table 2) is about three times longer than that of the young. Six of the skulls are complete, and one is represented by its posterior half. Skeleton 7 of a juvenile (including skull and lower jaws) is complete and articulated although the dorsal vertebrae are slightly displaced.

The following osteological description is based on the adult individual. The skull is complete but dorsoventrally flattened and is triangular in dorsal view. The antorbital region is longer than the postorbital portion, and it is approximately $42 \%$ of skull length. The external narial openings are dorsal but slightly posterior to the tip of the snout, as in other monjurosuchids (Gao and Li, 2007). The external nares are oblate in outline and separated by an internarial bar. A small bone fragment is displaced over the right naris. The orbit is larger than the much reduced upper temporal fenestra. The orbital margin is distinct and stands higher than the surrounding area, producing a shallow interorbital groove. The lateral temporal fenestra is completely closed by the expansion of the surrounding bones. The upper tooth count is not clear, due to the orientation of the skull.

There are 7 articulated cervical vertebrae separated slightly

Table 2. Measurements (mm) of new specimens of Philydrosaurus splendens (JPM-10-088)

\begin{tabular}{|c|c|c|c|c|c|c|c|}
\hline Morphological measurement & 1 & 2 & 3 & 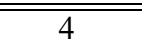 & 5 & 6 & 7 \\
\hline SLA & 70.6 & 24.8 & - & - & - & 21.9 & 22.7 \\
\hline SLB & 89.7 & 29.2 & & & & & \\
\hline Width between orbits & 5.1 & 1.6 & - & 20 & - & 1.7 & 1.8 \\
\hline Skull width between jugals & 36.4 & 15.6 & - & 15 & - & 16.8 & 16.1 \\
\hline Maximum width (between quadratojugal) & 48.2 & 17.9 & 18.4 & 18.5 & - & 22.6 & 21.9 \\
\hline Orbit length & 23.1 & 7.9 & - & 6.3 & 7.6 & 7.6 & 6.9 \\
\hline Orbit width & 13.8 & 6.2 & - & 5.4 & 5.0 & 6.1 & 6.1 \\
\hline Anteorbital Length & 37.3 & 9.0 & - & - & 8.6 & 8.7 & 7.5 \\
\hline Postorbital length & 31 & 12 & - & 12 & 12 & 12 & 12 \\
\hline Lower jaw length & 73 & - & - & - & - & - & - \\
\hline Body length (including skull) & 700 & 150 & - & 130 (est.) & 155 & 170 & 160 \\
\hline Body concavity & 120 & - & - & - & - & - & - \\
\hline Humerus length & 33 & - & - & - & - & - & 6.5 \\
\hline Humerus proximal end width & 11.8 & - & - & - & - & - & - \\
\hline Humerus distal end width & 12.4 & - & - & - & - & - & - \\
\hline Humerus mid shaft width & 4.6 & - & - & - & - & - & - \\
\hline Ulna length & 20 & - & - & - & - & - & 5 \\
\hline Ulna shaft width & 3.3 & - & - & - & - & - & - \\
\hline Radius length & 20 & - & - & - & - & - & - \\
\hline Radius shaft width & 3.1 & - & - & - & - & - & - \\
\hline Femur length & 42.3 & - & - & - & - & - & 9.1 \\
\hline Femur shaft width & 5.4 & - & - & - & - & 9.0 & 2.0 \\
\hline Tibia length & 31.3 & 6.7 & - & - & - & 7 & 7 \\
\hline Tibia shaft width & 5.1 & - & - & - & - & 1.2 & 1.1 \\
\hline Fibula length & 29.6 & - & - & - & - & 6.0 & 6.2 \\
\hline Fibula shaft width & 3.1 & - & - & - & - & 0.6 & 0.6 \\
\hline Metatarsal I-V length & $10,12,16,17,11$ & - & - & - & - & - & - \\
\hline
\end{tabular}

Individual 1 is considered to be an adult, whereas the other six animals are considered as juveniles. Antorbital length was measured from the tip to the level of the anterior margin of the orbit. est., estimated; SLA, skull length (measured from parietal to rostral end); SLB, skull length (measured from squamosal to rostral end); -, no data (not preserved or un-applicable). 
from the atlas and axis. The neural arches are fused with their corresponding centra. The neural spines of cervical vertebrae are narrower than these of dorsal and caudal vertebrae. There are 11 associated but not articulated dorsal vertebrae. Four vertebrae in the pelvic region bear transverse processes with wide distal ends indicating the presence of four unfused sacral vertebrae. There are 45 caudal vertebrae, which gradually become smaller distally. Caudal neural spines are wide and high and there is a distinct central ridge along the lateral surface of the centrum. The neural arches are fused with their corresponding centrum. No haemal arch is preserved.

The interclavicle and clavicles of the pectoral girdle are covered by the vertebral column, thus their detailed structures are not clear. The scapula and coracoid are not fused. The scapula is a slender flask-like element with a narrow blade and wider base, similar to these of Philydrosaurus proseilus (Gao and Fox, 2005) and Monjurosuchus splendens (Gao et al., 2007). The coracoid is partially exposed at its proximal end, it is broad and round.

The proximal and distal articulations of the humeri are ossified and expanded. The distal end is oriented at an angle with respect to the proximal end. A shallow groove appears on the posterior surface near the distal end. The ulna is slightly curved and expanded at both ends. It is slightly thicker than radius which is straight but both ends are not expanded. Five carpals are preserved naturally articulated with the proximal ends of metacarpals. Two bones articulate with the distal end of ulna and radius respectively. The ulnare is nearly square and larger than radiare. Due to the lost of several phalanges, the phalangeal formula is not clear. The claw is slightly curved with sharp tip.

The dorsal portion of the left ilium is covered by the transverse processes of the sacral vertebrae. Its articular end with the pubis is much larger than that with the ischium. The acetabulum is a shallow concavity. The posterior acetabular process is longer than its anterior process. The right ilium is covered by the transverse process of the sacral vertebrae. Ischium bears a developed postodorsal process. The pubis is square and plate-like with a small obturator foramen penetrating it.

The femur is curved with slightly expanded proximal end distal ends. The tibia is parallel to, and more robust than, the fibula. The proximal end of the tibia is wider than its distal end.

There are five tarsals preserved. The distal ends of metatarsals are expanded, and wider than the proximal ends. The fifth metatarsal is stout. All the digital elements of the manus and pes are well ossified. The pedal digit formula is 2-3-44-3. The fourth toe is longest and the first is the shortest.

All of skeletons are dorsoventrally preserved and exposed their dorsal sides, and the small individuals circle around the larger individual in the same bedding plane, suggesting that these were buried simultaneously. One of six small skeletons is in contact with the largest with another four individuals lying within $5-10 \mathrm{~cm}$ of the adult's body and the final individual lying within $40 \mathrm{~cm}$ (Fig. 2). The larger animal is almost entirely articulated except for the ribs and partial dorsal vertebrae but the ribs are placed very close to the body. All the individuals are preserved as a normal way (lying dorsal side upwards when excavated) suggesting minimal postmortem movement. There is no evidence observed of bone damage caused by predation or scavenging.

\section{DISCUSSION}

\subsection{Identification of JPM-10-088}

All the skeletons (JPM-10-088) are assigned to monjurosuchids, based on the following specific characters (Gao and $\mathrm{Li}, 2007$ ) in both the large and small individuals: proportionally short, wide, triangular skull; well-defined anterolateral process of frontal contacting lacrimal; postfrontal significantly larger than postorbital; presence of postfrontal/squamosal contact, excluding postorbital from border of upper temporal fenestra; deep V-shaped post-temporal incision at midline of occiput; and iliac blade short, rising roughly at an angle of $45^{\circ}$ from horizontal. However, the specimens (JPM-10-088) bearing the following characters: skull elongate; narial openings and orbits elongate; possession of distinct 'supratemporal trough' formed by postorbital and postfrontal and containing supratemporal fenestra; antorbital ridge developed on dorsal surface of prefrontal; postfrontal ridge forming medial border of 'supratemporal trough', which are diagnostic features of Philydrosaurus (Gao and Fox, 2005; Gao et al., 2007, 2013). The adult of JPM-10-088 is identical to the skull of the holotype Philydrosaurus, thus JPM-10-088 is identified as Philydrosaurus. Philydrosaurus is a member of Monjurosuchidae, which is a clade of small, blunt-snouted choristoderes and is currently known only from two closely related genera (Monjurosuchus and Philydrosaurus) from the Early Cretaceous volcanic ash deposits of western Liaoning Province, China (Gao et al., 2000; Gao and Li, 2007; Gao et al., 2007, 2013).

All small Philydrosaurus individuals (JPM-10-088) are approximately a quarter the size of the large individual in length (Fig. 1). One small individual is overlapped by the tail of the larger animal, but was not within its body. The small individuals show some ontogenetic features suggesting that they are younger than the larger individual. For instance, both ends of all long bones (humeri, femora, tibiae, ulnae) in the small individuals do not show well-defined articulation surfaces or are not as well ossified as the largest animal (Fig. 3). Also the orbit is round whilst that of the larger animal is longer than wide; the ratio of the tibia to femur is constant, about 0.74; and the long bones in smaller Philydrosaurus are straight rather than curved as in the larger individual. The tails of the smaller animals are fully ossified 

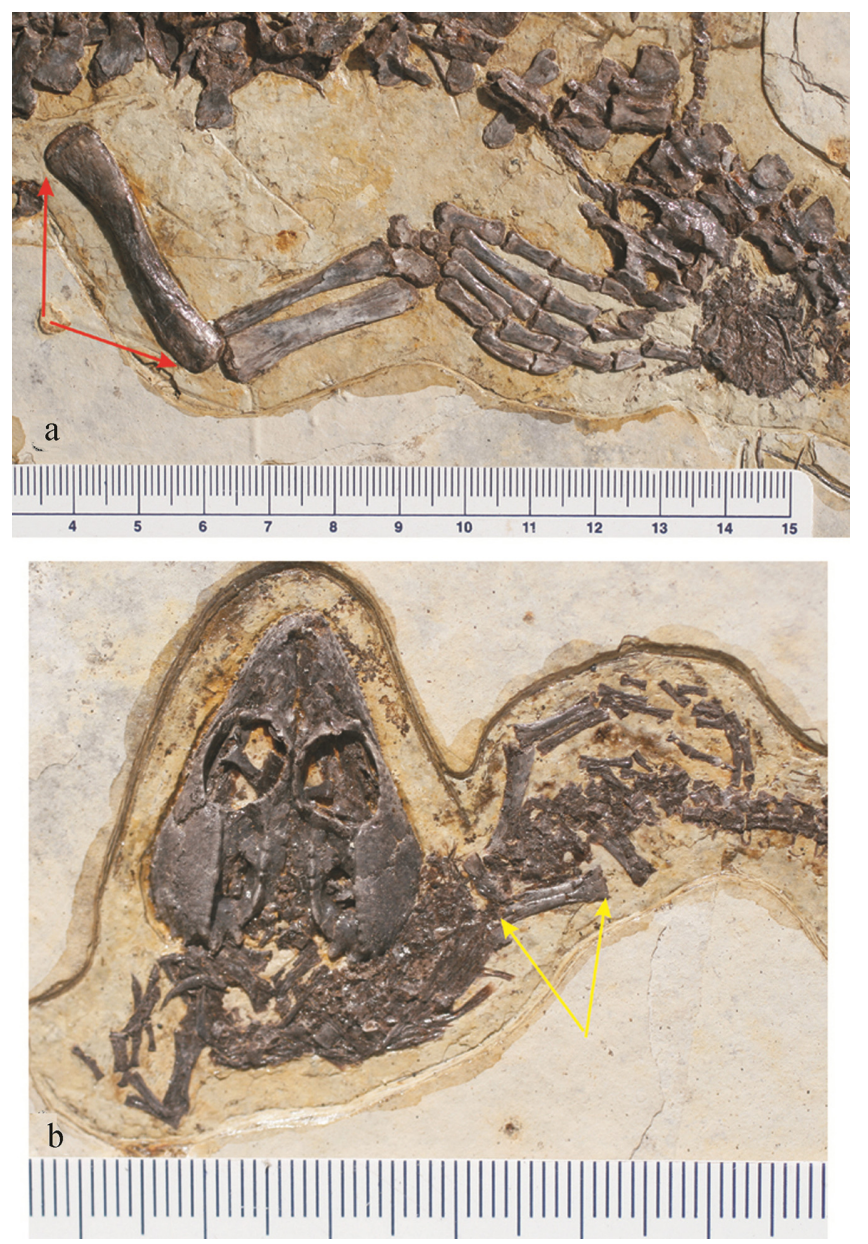

Fig. 3. Comparison of ends of long bones in (a) adult and (b) juvenile Philydrosaurus (JPM-10-088) showing the un-ossified long bone ends in young. Arrows point to the ends of femora. Scales are in $\mathrm{mm}$.

and the number of caudal vertebrae is 45 in all individuals.

In conclusion, these characteristics suggest that the largest individual is an adult Philydrosaurus surrounded by juveniles of the same species. Moreover, given that the smaller individuals are of similar sizes, we interpret this specimen as indicating an adult with its offspring, apparently from the same clutch. Morphometrics of the six young individuals suggest that they could not fit within the adult body cavity, which precludes them from being neonates from the associated adult.

\subsection{Reproductive Biology of Choristoderes}

This specimen is the latest in an increasingly detailed collection of choristoderes exhibiting different levels of reproduction and parental care. An adult specimen of Hyphalosaurus baitaigouensis have been found in Early Cretaceous rocks in China that is associated with an obvious juvenile individual, and in another case there is a large individual associated with apparently leathery-shelled eggs enclosing coiled embryos (Ji et al., 2006). Another find is of an adult has two eggs containing well-developed embryos and eggshells comparable to parchment-shells of Lepidosaurs (Ji et al., 2010). This association between an adult and eggs containing welldeveloped embryos may be coincidental but Hou et al. (2010) suggested that the eggs were buried along the shoreline. By stark contrast, another specimen of Hyphalosaurus baitaigouensis contains up to 18 near-term embryos within its body cavity and was considered by Ji et al. (2010) as indicating viviparity comparable to that seen in ichthyosaurs (Deeming et al., 1993), mesosaurs (Piñeiro et al., 2012), sauropterygians (Renesto et al., 2003; Cheng et al., 2004; O'Keefe and Chiappe, 2011) and mosasaurs (Caldwell and Lee, 2001). A possible explanation of these different fossil finds is that this species (perhaps all choristoderes) exhibited a form of lecithotrophic ovoviviparity with retention of large-yolked parchment-shelled eggs that were laid, probably on land, immediately before neonates hatched. Only further specimens of Hyphalosaurus or other choristoderes will help resolve whether this interpretation is correct.

Choristodera has provided the only known example of a developmental malformation in the fossil record. A small late-term embryonic, or neonatal, choristodere has been found with two heads and associated cervical vertebrae attached to one thorax (Buffetaut et al., 2007).

Not all small skeletons inside the body cavity have been interpreted as embryos. A specimen of Monjurosuchus has been found to exhibit cannibalism (Wang et al., 2005). The adult has seven small skulls, all of comparable size, within its abdomen and apparently of the same species. This specimen is interpreted as indicating an adult that had preyed upon a clutch of seven neonates, which were of comparable sizes to each other (Wang et al., 2005). At around $22 \mathrm{~mm}$, these ingested skulls were around two-thirds the length of the skulls of small Philydrosaurus described here suggesting that they were indeed at an earlier ontogenetic stage than observed in JPM-10-088.

There are two hypotheses that could explain the small individuals of Philydrosaurus in JPM-10-088: (1) these are neonates, ejected from the adult female's body after its death, or (2) juveniles receiving some form of post-natal parental care. Using a relationship between adult length and hatchling length for extant lizards (Andrews, 1982) the predicted total neonatal length for an adult Philydrosaurus measuring $790 \mathrm{~mm}$, is $160 \mathrm{~mm}$ but the small specimens range from 170-200 $\mathrm{mm}$. In addition, the skulls of the small individuals in JPM-10-088 are 150\% larger than the skulls of the small predated individuals found within the body of M. splendens (IVPP ${ }^{1}$ V13761). Therefore, although post-cranial bone development appears to be incomplete, indicating an early ontogenetic stage, it is likely that the small individuals associated with this adult in JPM-10-088 are not neonatal. Their

IVPP, the Institute of Vertebrate Paleontology and Paleoanthropology, Chinese Academy of Sciences, Beijing, China 


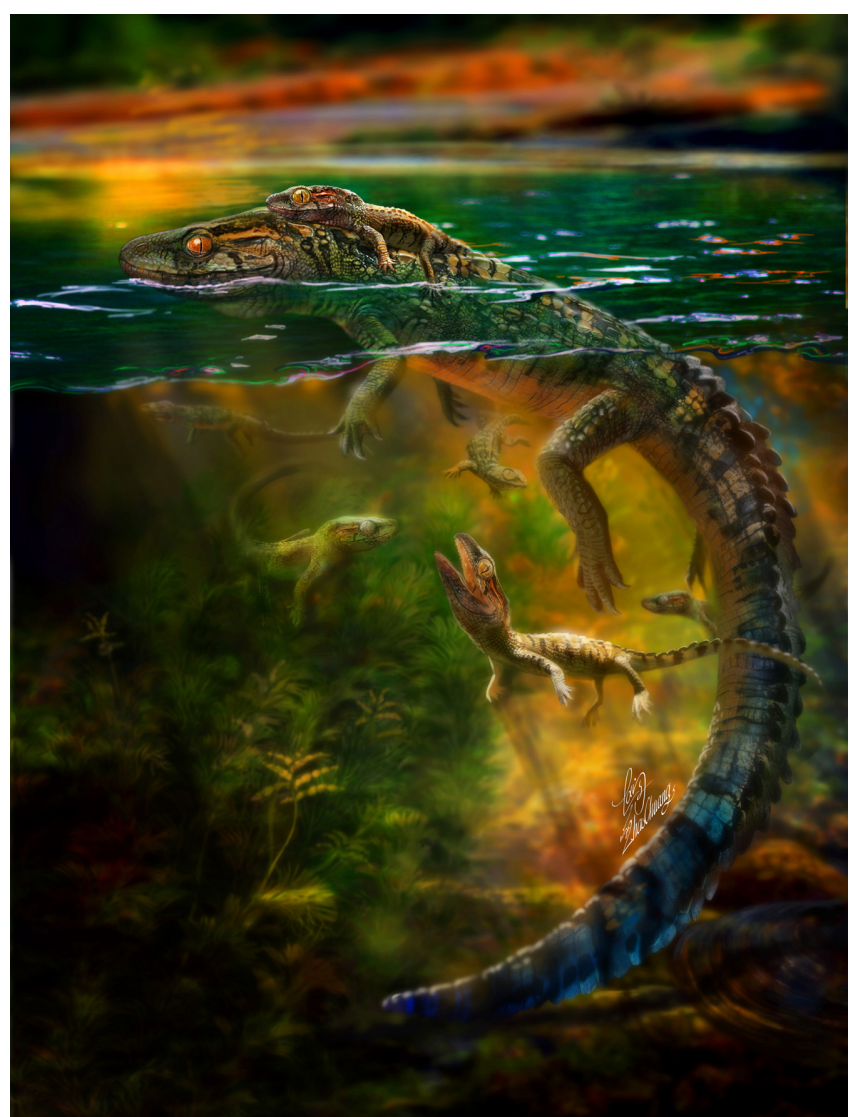

Fig. 4. The living scene of the adult Philydrosaurus and its babies (JPM-10-088) (Drawn by Zhao Chuang).

small size, and high degree of articulation, suggests that these animals were juvenile Philydrosaurus that were preserved with this adult but it is not possible to be more precise about their developmental age when they were preserved.

The fact that six young monjurosuchids surround what appears to be an adult suggests the animals were in natural close proximity at the time of death. Although it is possible that the individuals were all swept together during or soon after the event that killed them it is feel that this specimen more likely represents an instance of post-natal parental care (Fig. 4). This hypothesis is supported by the close association of an adult and a juvenile of Hyphalosaurus (Ji et al., 2006).

\section{IMPLICATION FOR THE EVOLUTION OF PARENTAL CARE IN DIAPSIDS}

Parental care of neonatal and young juvenile individuals is observed in modern crocodilians, which by their physical presence protect their hatchlings against potential predators (Magnusson, 1980; Cintra, 1989). Modern birds exhibit a wide range of post-natal care, including simple protection of precocial offspring as exhibited by the ostrich Struthio camelus (Bertram, 1992) through to provision of food and protection of altricial offspring of passerines (Burt et al., 2007). Unequivocal evidence of post-natal parental care in the fossil record is extremely rare and is only observed in a 'Pelycosaur' from the Permian and ornithischian dinosaurs from the Cretaceous (Botha-Brink and Modesto, 2007; Meng et al., 2004; Varricchio et al., 2007). The only other suggestion of possible post-natal parental care could be attributed to trackways by sauropods (Griebeler and Werner, 2011; Lockley, 1994) that exhibit a wide range of print sizes and have been interpreted as indicating an association between juveniles and adults, although this has been questioned recently (Timothy et al., 2009). The sex of the adult animals involved in these cases of post-natal parental care is unknown. Although in Dinosauria, paternal care has been suggested to have originated in some non-avian coelurosaur dinosaurs (Varricchio et al., 2008), re-analysis has now shown that this interpretation is incorrect (Birchard et al., 2013). The sacral ribs of the adult Philydrosaurus are not fused either to the sacrum proximally or to the ilia distally, indicating that the pelvis would have been flexible. A similar condition is observed in the gravid females of the sauroptrygian Keichousaurus hui (Cheng et al., 2004), and implies that this adult of Philydrosaurus is a female.

Post-natal parental care in Philydrosaurus and Hyphalosaurus (Ji et al., 2006) may be potential evidence for this behavior as the ancestral condition in diapsids. The phylogenetic position of Choristodera is controversial. It is variously placed within Archosauromorpha (Gauthier et al., 1989) or a sister taxon to Archosauromorpha (deBraga and Rieppel, 1997), or basal lepidosauromorphs (Müller, 2003), or a more basal position within Diapsida (Dilkes, 1998; Gao and Fox, 1998). Discussion of the phylogenetic position of Choristodera is beyond the scope of this study, but the idea of its position within Diapsida is accepted here. If we follow Gauthier et al. (1989) and deBraga and Rieppel (1997), it suggests that post-natal parental care could be the ancestral condition in basal archosauriforms, most likely in Archosauria. If we follow the phylogenetic position of Choristodera (Gao and Fox, 1998), it suggests that the maternal care in christoderan Philydrosaurus represents the earliest record of this behavior in diapsids. Mapping parental care on a general phylogeny of the major amniotic groups (Müller et al., 2010), using Mesquite (Maddison and Maddison, 2011) and under reversible (Fitch) parsimony, showed that postnatal parental care appeared to be the ancestral condition for all amniotes (Fig. 5). Few post-natal parental care in modern testudines and squamates may be a derived condition independently acquired in the two groups.

In conclusion, the discovery of young within the mother in the choristoderan Hyphalosaurus documents live birth (ovo-viviparity) in choristoderes ( $\mathrm{Ji}$ et al., 2010), which is the first report for freshwater aquatic reptiles - other instances of live birth are for marine aquatic species (Deeming et al., 1993; Piñeiro et al., 2012; Renesto et al., 2003; Cheng et al., 


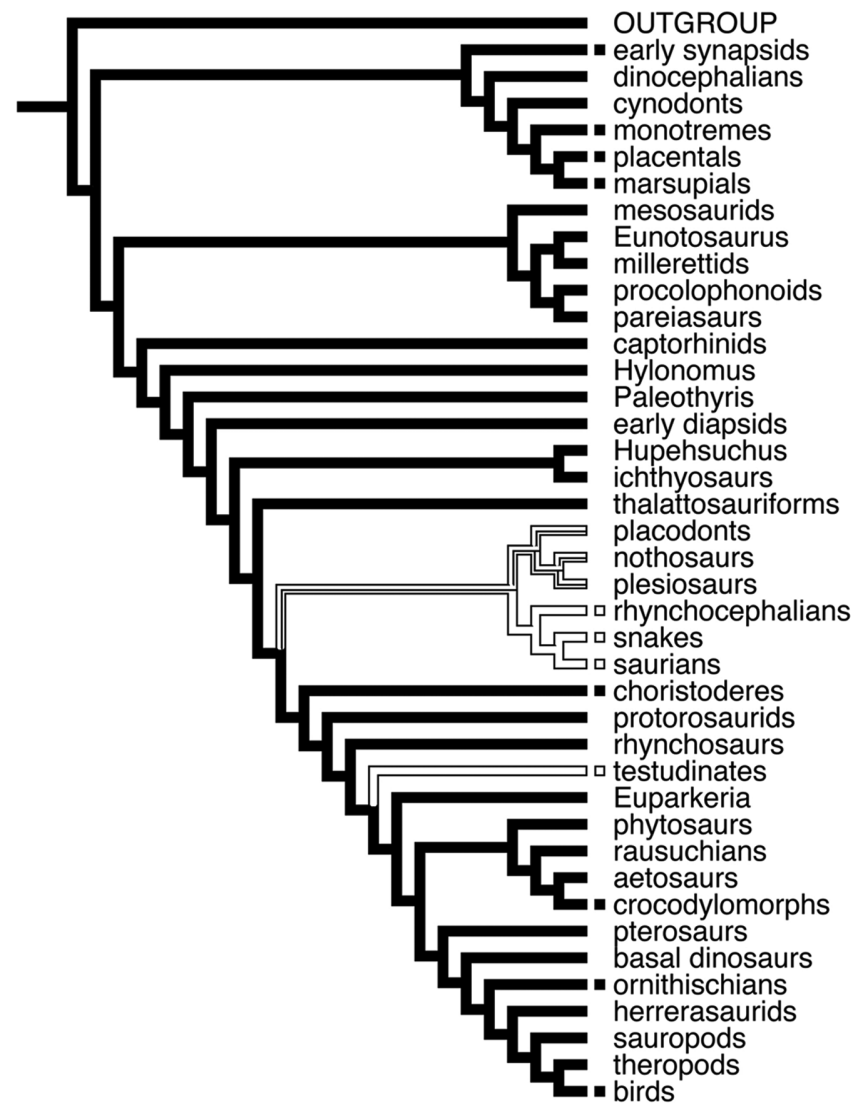

Fig. 5. Pattern of evolutionary relationships for post-natal parental care based on the evidence of such in extinct and extant groups. Post-natal care is shown by black lines and lack of this behavior is by white lines. ( $\square)$ and ( $\square$ ) indicate taxa where evidence of postnatal parental care is available in extinct or extant taxa. Branches with one color indicate no ambiguity in the pattern of distribution of alternative states. Two colors indicate equally possible alternative conditions. Paring of this phylogeny to include only those groups where evidence was available had no effect on the basic pattern.

2004; O'Keefe and Chiappe, 2011; Caldwell and Lee, 2001). Live birth may reflect an adaptive strategy for reproduction in aquatic animals perhaps associated with avoidance from predation by contemporaneous terrestrial carnivores (Ji et al., 2010). Whether Philydrosaurus had live birth in the same way as Hyphalosaurus is uncertain, but the possible close phylogenetic relationship between monjurosuchids and hyphalosaurids is suggestive that choristoderes in the Jehol Biota shared a reproductive strategy of live birth and postnatal parental care. That Philydrosaurus shows parental care of the young after hatchling suggests protection by the adult, presumably against predators. Their relatively small size would have meant that choristoderes were probably exposed to high predation pressure and strategies, such as live birth and post-natal parental care, may have improved survival of the offspring. A test of whether post-natal parental care is an ancestral behavior that has persisted in the evolutionary development of amniotes, will depend on future fossil discoveries.
ACKNOWLEDGMENTS: We thank Louis Jacobs (SMU, USA) and Xiao-Chun Wu (Canadian Museum of Nature, Canada) who reviewed the first draft of the paper and made constructive suggestions. Marcello Ruta helped with the use of Mesquite in the estimation of ancestral behavior patterns. Zhenyuan Sun offered the specimen for scientific research. The specimen was prepared by Zhang Y-Q (CAGS). The living scene of Philydrosaurus was drawn by Zhao Chuang. J. Lü was supported by grants from the National Natural Science Foundation of China (Grant No. 41272022, 90914003) and the China Geological Survey (Grant 12120114026801). Y. K was financially supported by JSPS KAKENHI Grant Number 24540494.

\section{REFERENCES}

Andrews, R.M., 1982, Patterns of growth in reptiles. In: Gans, C. and Pough F.H. (eds.), Biology of the Reptilia, Vol. 13: Physiology D. Academic Press, London, 273-320.

Bertram, B.C.R., 1992, The Ostrich Communal Nesting System. Princeton University Press, Princeton, 196 p.

Birchard, G.F., Ruta, M., and Deeming, D.C., 2013, Evolution of parental incubation behaviour in dinosaurs cannot be inferred from clutch mass in birds. Biology Letters, e20130036.

Botha-Brink, J. and Modesto, S.P., 2007, A mixed-age classed 'Pelycosaur' aggregation from South Africa: earliest evidence of parental care in amniotes? Proceedings of the Royal Society B: Biological Sciences, 274, 2829-2834.

Buffetaut, E., Li, J., Tong, H., and Zhang, H., 2007, A two-headed reptile from the Cretaceous of China. Biology Letters, 3, 80-81.

Bureau of Geology and Mineral Resources of Liaoning Province, 1989, Regional geology of Liaoning Province. Geological Publishing House, Beijing, $856 \mathrm{p}$.

Burt, D.B., Coulter, P.F., and Ligon, J.D., 2007, Evolution of parental care and co-operative breeding. In: Jamieson, B.G.M. (ed.), Reproductive Biology and Phylogeny of Birds, Part B. Science Publishers, Enfield, 295-326.

Caldwell, M.W. and Lee, M.S.Y., 2001, Live birth in Cretaceous marine lizards (mosasauroids). Proceedings of the Royal Society B: Biological Sciences, 268, 2397-2401.

Cheng, Y.N., Wu, X.C., and Ji, Q., 2004, Triassic marine reptiles gave birth to live young. Nature, 432, 383-386.

Cintra, R., 1989, Maternal care and daily pattern of behavior in a Family of Caimans, Caiman yacare in the Brazilian Pantanal. Journal of Herpetology, 23, 320-322.

deBraga, M. and Rieppel, O., 1997, Reptile phylogeny and the interrelationships of turtles. Zoological Journal of the Linnean Society, 120, 281-354.

Deeming, D.C., Halstead, L.B., Manabe, M., and Unwin, D.M., 1993, An ichthyosaur embryo from the Lower Lias (Jurassic: Hettangian) of Somerset, England, with comments on the reproductive biology of ichthyosaurs. Modern Geology, 18, 423-442.

Dilkes, D., 1998, The Early Triassic rhynchosaur Mesosuchus browni and the interrelationships of basal archosauromorph reptiles. Philosophical Transactions B, 353, 501-541.

Endo, R., 1940, A new genus of Thecodontia from the Lycoptera beds in Manchoukuo. Bulletin of Central National Museum of Manchoukuo, 2, 1-14.

Gao, K.Q., 2007, Phylogenetic and ecomorphic diversity and biogeographic evolution of Choristodera as a distinct diapsida clade. Journal of Palaeogeography, 9, 541-550.

Gao, K.Q. and Fox, R.C., 1998, New choristoderes (Reptilia: Diapsida) from the Upper Cretaceous and Palaeocene, Alberta and Saskatchewan, Canada, and phylogenetic relationships of Choristo- 
dera. Zoological Journal of the Linnean Society, 124, 303-353.

Gao, K.Q. and Fox, R.C., 2005, A new choristodere (Reptilia: Diapsida) from the Lower Cretaceous of western Liaoning Province, China, and phylogenetic relationships of Monjurosuchidae. Zoological Journal of the Linnean Society, 145, 427-444.

Gao, K.Q. and Li, Q.G., 2007, Osteology of Monjurosuchus splendens (Diapsida: Choristodera) based on a new specimen from the Lower Cretaceous of western Liaoning, China. Cretaceous Research, 28, 261-271.

Gao, K.Q., Evans, S., Ji, Q., Norell, M., and Ji, S.A., 2000, Exceptional fossil material of a semi-aquatic reptile from China: the resolution of an enigma. Journal of Vertebrate Paleontology, 20, 417-421.

Gao, K.Q., Ksepka, D., Hou, L.H., Duan, Y., and Hu, D.Y., 2007, Cranial morphology of an Early Cretaceous monjurosuchid (Reptilia: Diapsida) from Liaoning Province of China and evolution of the choristoderan palate. Historical Biology, 19, 215-224.

Gao, K.Q., Zhou, C.F., Hou, L.H., and Fox, R.C., 2013, Osteology and ontogeny of Early Cretaceous Philydrosaurus (Diapsida: Choristodera) based on new specimens from Liaoning Province, China. Cretaceous Research, 45, 91-102.

Gauthier, J.A., Cannatella, D., Queiroz, K., deKluge, A.G., and Rowe, T., 1989, Tetrapod phylogeny. In: Fernholm, B., Bremer, K., and Jörnvall, H., (eds.), The Hierarchy of Life. Elsevier Science Publishers, p. 337-353.

Griebeler, E.M. and Werner, J., 2011, The life history of sauropod dinosaurs. In: Klein, N., Remes, K., Gee, C.T., and Sander, P.M. (eds.), Biology of the Sauropod Dinosaurs: Understanding the Life of Giants. Indiana University Press, p. 263-275.

Hou, L.H., Li, P.P., Ksepka, D.T., Gao, K.Q., and Norell, M.A., 2010, Implications of flexible-shelled eggs in a Cretaceous choristoderan reptile. Proceedings of the Royal Society B: Biological Sciences, 277, 1235-1239.

Ji, Q., Ji, S.A., Lü, J.C., You, H.L., and Yuan, C.X., 2006, Embryos of Early Cretaceous choristodera (Reptilia) from the Jehol biota in Western Liaoning, China. Journal Paleontological Society of Korea, 22, 111-118.

Ji, Q., Wu, X.C., and Cheng, Y.N., 2010, Cretaceous choristoderan reptiles gave birth to live young. Naturwissenschaften, 97, 423428.

Lockley, M.G., 1994, Dinosaur ontogeny and population structure: interpretations and speculations based on fossil footprints. In: Carpenter, K., Hirsch, K.F., and Horner, J.R. (eds.), Dinosaur Eggs and Babies. Cambridge University Press, Cambridge, p. 347-365.
Maddison, W.P. and Maddison, D.R., 2011, Mesquite: a modular system for evolutionary analysis. Version 2.75 , http://mesquiteproject.org.

Magnusson, W.E., 1980, Hatching and crèche formation by Crocodylus porosus. Copeia, 1980, 359-361.

Meng, Q., Liu, J., Varricchio, D.J., Huang, T., and Gao, C., 2004, Parental care in an ornithischian dinosaur. Nature, 431, 145-146.

Müller, J., 2003, Early loss and multiple return of the lower temporal arcade in diapsid reptiles. Naturwissenschaften, 90, 473-476.

Müller, J., Scheyer, T.M., Head, J.J., Barrett, P.M., Wemeburg, I., Ericson, P.G.P., Pol, D., and Sánchez-Villagra, M.R., 2010, Homeotic effect, somitogenesis and the evolution of vertebral numbers in recent and fossil amniotes. Proceedings of the National Academy of Sciences of the United States of America, 107, 2118-2123.

O'Keefe, F.R. and Chiappe, L.M., 2011, Viviparity and K-selected life history in a Mesozoic marine plesiosaur (Reptilia, Sauropterygia). Science, 333, 870-873.

Piñeiro, G., Ferigolo, J., Meneghel, M., and Laurin, M., 2012, The oldest known amniotic embryos suggest viviparity in mesosaurs. Historical Biology, 24, 620-630.

Renesto, S., Lombardo, C., Tintori, A., and Danini, G., 2003, Nothosaurid embryos from the middle Triassic of northern Italy: an insight into the viviparity of nothosaurs? Journal of Vertebrate Paleontology, 23, 957-960.

Timothy, S., Myers, T.S., and Fiorillo, A.R., 2009, Evidence for gregarious behavior and age segregation in sauropod dinosaurs. Palaeogeography Palaeoclimate Palaeoecology, 274, 96-104.

Varricchio, D.J., Martin, A.J., and Katsura, Y., 2007, First trace and body fossil evidence of a burrowing, denning dinosaur. Proceedings of the Royal Society B: Biological Sciences, 274, 1361-1368.

Varricchio, D.J., Moore, J.R., Erickson, G.M., Norell, M.A., Jackson, F.D., and Borkowski, J.J., 2008, Avian paternal care had dinosaur origin. Science, 322, 1826-1828.

Wang, X., Miao, D., and Zhang, Y., 2005, Cannibalism in a semi-aquatic reptile from the Early Cretaceous of China. Chinese Science Bulletin, 50, 281-283.

Zhang, W. and Gao, K.Q., 2014, Early Cretaceous evolution of choristoderes in western Liaoning based on geographic and stratigraphic evidence. Journal of Palaeogeography, 16, 205-216.

Zhou, Z., Barrett, P.M., and Hilton, J., 2003, An exceptionally preserved Lower Cretaceous ecosystem. Nature, 421, 807-814.

Manuscript received July 8, 2014

Manuscript accepted September 17, 2014 